\title{
Surgical treatment of hyperinsulinaemic hypoglycaemia in infancy and childhood
}

\author{
L Spitz, R K Bhargava, D B Grant, J V Leonard
}

\begin{abstract}
Despite a greater awareness of hyperinsulinaemic hypoglycaemia, one in three patients has some degree of mental retardation by the time the diagnosis is made. The diagnosis is established by demonstrating high plasma insulin concentrations during an episode of hypoglycaemia. Twenty one hyperinsulinaemic infants and children were referred for surgical treatment after failing to respond to medical management. The surgical procedure of choice is a $95 \%$ pancreatectomy. Recurrence of the hypoglycaemia may develop after less radical resections as occurred in one patient who then underwent an extended resection 72 hours postoperatively. Patients who fail to respond to optimal medical treatment should be referred for surgery early and not as a last resort if permanent neurological damage is to be avoided.
\end{abstract}

Hypoglycaemia may be defined as a blood glucose concentration of less than $2 \cdot 2 \mathrm{mmol} / \mathrm{l}$. In neonates it is usually transient and responds readily to additional enteral intake of glucose or in more refractory cases to intravenous glucose infusion. Severe intractable hypoglycaemia is rare and more difficult to manage. Delay in recognising the problem and starting treatment exposes the infant to the risk of mental retardation.

In patients with persistent hypoglycaemia it is important to exclude other endocrine disorders, for example hypopituitarism, or inborn errors of metabolism, for example glycogen storage disease. Hyperinsulinism accounts for approximately $1 \%$ of all cases with hypoglycaemia, ${ }^{1}$ but it is the most common cause of persistent neonatal hypoglycaemia. Laidlaw in 1938, coined the term 'nesidioblastosis' (from Greek 'island') to describe the budding of islet cells from the pancreatic ducts. ${ }^{2}$ The specific histological findings in infants with intractable hypoglycaemia were first described by Yakovac et al in $1971 .{ }^{3}$ The pancreatic tissue shows diffuse $\beta$ cell and islet cell hyperplasia that is associated with fetal type budding from the pancreatic ducts and disruption of cell ratios and cell to cell contact within the exocrine pancreas. ${ }^{4}$

The diagnosis of hyperinsulinism is made on the following criteria ${ }^{5}$ :

(1) Inappropriately raised plasma insulin concentrations for blood glucose values.

(2) Glucose infusion rate $>10 \mathrm{mg} / \mathrm{kg} /$ minute needed to maintain a blood glucose concentration $>2 \mathrm{mmol} / \mathrm{l}$ (in the absence of glycosuria).
(3) Low plasma free fatty acids and blood ketone bodies during hypoglycaemia.

(4) A glycaemic response to glucagon despite hypoglycaemia.

The condition is inherited as an autosomal recessive.$^{6-10}$ It has been described in association with familial multiple endocrine adenomatosis ${ }^{11}$ and been implicated in sudden infant death syndrome. ${ }^{12-14}$

Medical treatment consists of providing sufficient glucose to prevent the hypoglycaemia, which usually requires an intravenous infusion of $15-20 \%$ glucose. Diazoxide is still the mainstay of the medical management. It inhibits glucose stimulated insulin secretion and doses of up to $20 \mathrm{mg} / \mathrm{kg}$ body weight/day may be necessary. Its action is potentiated by the diuretic chlorothiazide. Somatostatin inhibits insulin release and this hormone or one of its analogues is a useful short term therapeutic adjunct in the preoperative preparation of the infant with refractory hyperinsulinism. ${ }^{15}$ Tolerance may develop ${ }^{16}$ and surgical treatment is indicated if the patient remains dependent on intravenous glucose.

Patients not responding to optimal medical treatment should be offered surgery at an early stage and not as a last resort. The results of surgery vary according to the extent of the pancreatic resection. The recurrence rate is unacceptably high when the resection is conservative $(75-80 \%$ pancreatectomy), whereas total pancreatectomy inevitably leads to permanent diabetes and exocrine deficiency. A $95 \%$ resection produces the best overall results. ${ }^{17}$

\section{Patients and methods}

PATIENTS

In the eight year period, 1982-90, 21 infants and children with severe persistent hypoglycaemia unresponsive to medical treatment were referred for surgical treatment. There were 11 boys and 10 girls whose ages ranged from 8 days to 5 years (fig 1 ) and birth weights ranged from 2680 to $6800 \mathrm{~g}$. Seventeen $(80 \%)$ of the infants presented with central nervous system manifestations in the form of twitchings, tremors, limpness, or irritability with or without convulsions within the first three days of life. In three patients who had already had clear evidence of mental retardation presentation was delayed for between 7-24 weeks.

The diagnosis of hyperinsulinism was made according to strict biochemical criteria. Inappropriately high concentrations of plasma insulin were recorded during episodes of hypoglycaemia in all patients (fig 2). Plasma insulin 


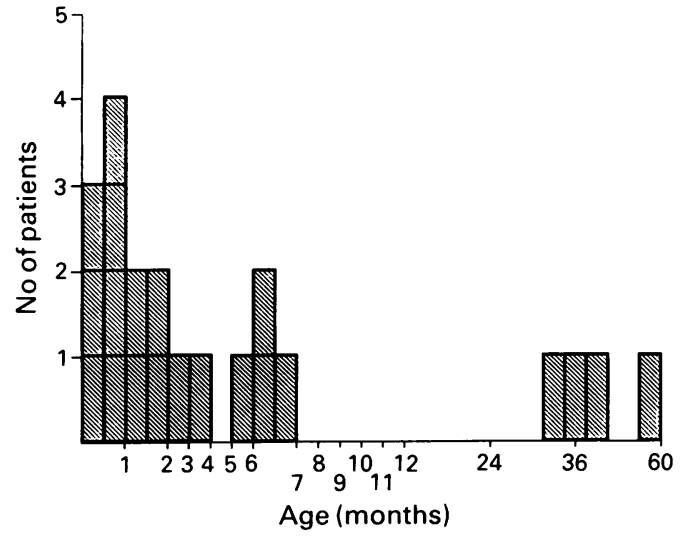

Figure 1 Histogram showing the age of the patients at operation.

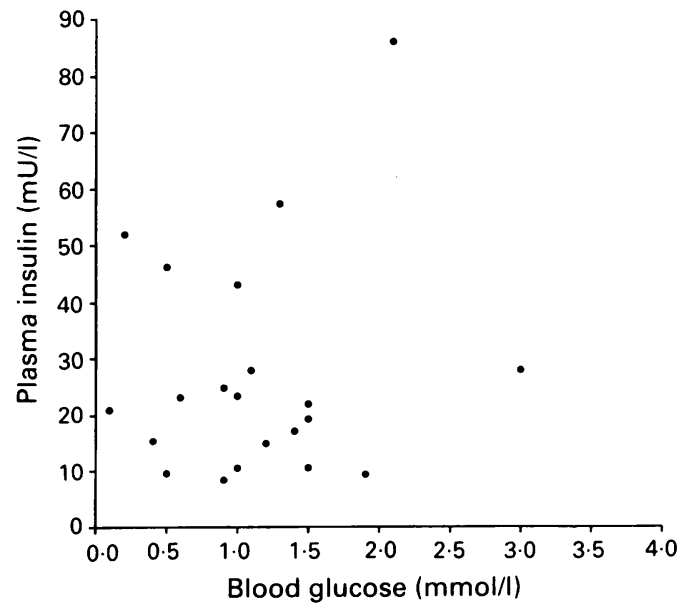

Figure 2 Concentrations of plasma insulin and blood glucose in the patients (to convert mU/l to pmol/l multiply by $7 \cdot 175$ ).

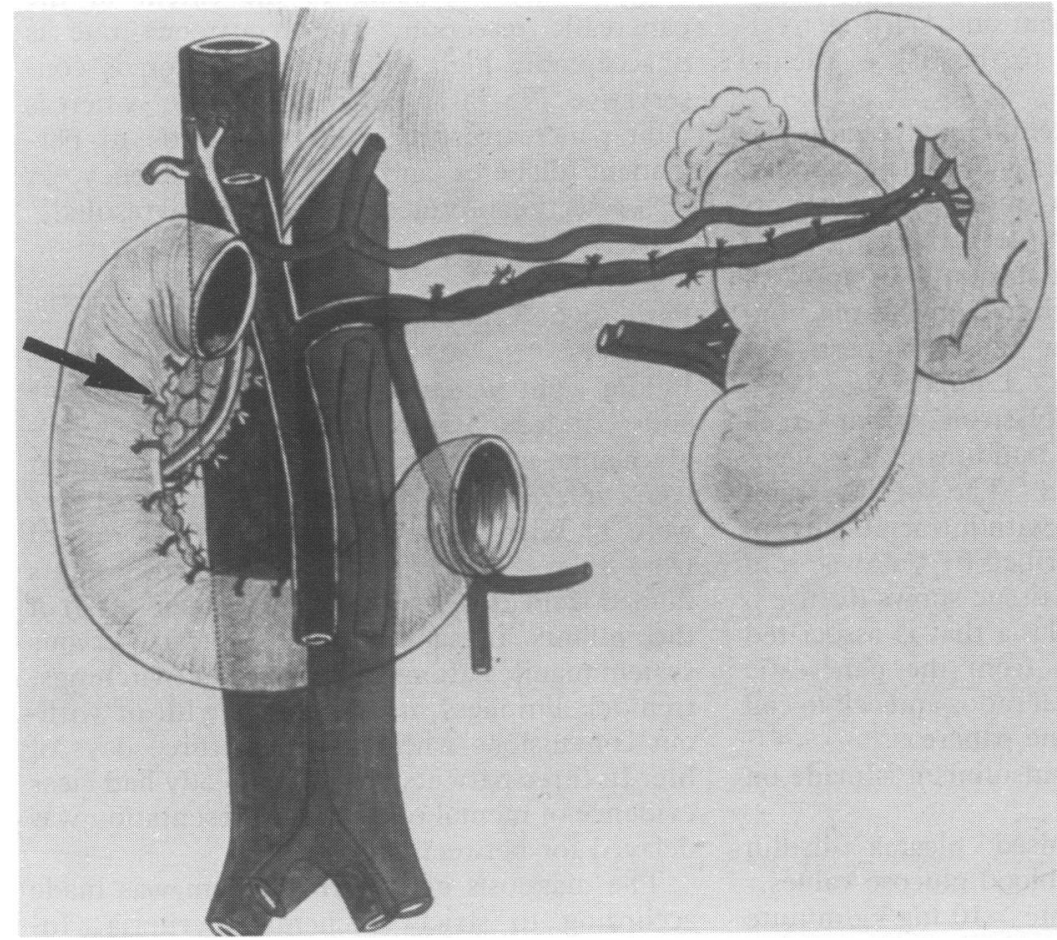

Figure 3 Diagram showing 95\% pancreatectomy. The arrow indicates the remnant of pancreas between the common bile duct and the concavity of the duodenum. Note the intact splenic vessels with multiple ligatures of short pancreatic branches. concentrations ranged from 8.4 to $86 \mathrm{mU} / \mathrm{l}$ with a mean of $27 \cdot 1 \mathrm{mU} / 1(60.3$ to $617 \cdot 1 \mathrm{pmol} / \mathrm{l}$, mean $194.4 \mathrm{pmol} / \mathrm{l})$.

Diagnostic imaging, including ultrasound scan, computed tomography in most patients, selective coeliac angiography in two, and high resolution magnetic resonance imaging in one patient were singularly unhelpful.

All patients had hepatomegaly, which was considerable in seven infants. Three patients had moderate hypertension and three developed clinical cardiac failure secondary to large volumes of glucose solutions required to achieve normoglycaemia in combination with high doses of diazoxide. Somatostatin was used preoperatively in two patients as a short term measure to control the hypoglycaemia.

Surgery was undertaken as soon as it became evident that the patient could not be maintained on medical treatment alone.

\section{OPERATIVE PROCEDURE}

Via a generous upper abdominal transverse muscle-cutting incision, a thorough laparotomy was carried out in search of ectopic pancreatic tissue. The entire pancreas was carefully exposed and examined for the presence of an adenoma, which when present appeared as a reddishbrown nodule on the surface of the greyish pancreas. These lesions were excised and submitted for frozen section histological examination, but because of the coexistence of adenoma and nesidioblastosis particularly in infancy, a full $95 \%$ pancreatectomy was carried out. The tail of the pancreas was carefully dissected off the hilum of the spleen and the body of the pancreas mobilised by meticulously exposing and ligating the numerous short pancreatic vessels arising from the splenic vessels. Great care was taken to preserve the splenic vessels to ensure viability of the spleen. Once the dissection had been carried out to the right of the superior mesenteric vessels, attention was turned to the uncinate process which projects posterior to the superior mesenteric vein. Resection of the uncinate process was regarded as an essential step in the operative procedure. After positively defining the course of the common bile duct, the pancreas to the left of the common duct and most of the gland within the concavity of the duodenum was excised. The main pancreatic duct was occasionally identified and ligated. The only pancreatic tissue remaining consisted of that part of the gland between the duodenum and the common bile duct and a sliver of tissue on the medial wall of the second part of the duodenum. This represented approximately $5 \%$ of the total volume of pancreatic tissue (fig 3). Bleeding from the raw surface of the gland was meticulously controlled and the wound was closed with a suction drain to the pancreatic bed.

\section{Results}

There was no mortality after the $95 \%$ pancreatectomy. One patient had a slightly lesser resection due to the presence of pancreatitis and fibrosis. Hypoglycaemia recurred posto- 
peratively and a further resection was carried out on the third postoperative day. Intraoperative injury to the common bile duct was recognised in two infants. In both cases a end to side choledochoduodenostomy was carried out without any immediate or long term effects. Two patients developed adhesion intestinal obstruction within 18 months of surgery, one responding to conservative treatment and the other requiring surgical correction.

Histological examination of the resected pancreas confirmed the diagnosis of nesidioblastosis in all patients. In two an additional pancreatic adenoma was noted in the resected specimen, one of which was recognised at surgery.

Varying degrees of hyperglycaemia occurred in all patients postoperatively. In most infants it developed within 24 hours of surgery and was transient, lasting a few days. Careful monitoring in the immediate postoperative period is, therefore, necessary. Prolonged hyperglycaemia lasting up to 18 months was encountered in four patients and required treatment with insulin. One patient is permanently diabetic; control has been difficult and a total of 4-8 units of insulin daily is required.

Seven patients were referred from abroad and are reportedly doing well on return home. No patient has shown a deterioration of mental function. Exocrine pancreatic function is borderline or low in most cases but only three have evidence of steatorrhoea and two have intolerance to fatty food. Two children require pancreatic exocrine supplementation.

\section{Discussion}

The largest review of neonatal hypoglycaemia by Tudor abstracted 122 articles detailing 497 cases published between $1926-1986 .{ }^{18}$ Whereas before 1975 the diagnosis of islet cell adenoma was frequent, it has now been superceded by nesidioblastosis. We have reviewed 198 cases published since $1982^{10} 19-45$ and compared them with our 21 cases treated over the same period.

The aetiology and pathogenesis of nesidioblastosis remains unknown. Some authors have described the condition under different names, for example islet cell dysmaturation syndrome, ${ }^{46}$ multifocal ductuloinsular proliferation, ${ }^{47}$ but the morphological findings are similar with diffuse involvement of the pancreas. Although it is clear that the number of islet cells relative to the rest of the pancreas is highest in the newborn period, it is not known what factors regulate the formation of the $\beta$ cells in the embryo and postnatally.

There is an important genetic component in neonatal nesidioblastosis as shown by the familial occurrence. Eleven siblings from five families have been reported ${ }^{6-8} 10$ and autosomal recessive inheritance is likely. Becker et al reported two patients with nesidioblastosis who had a sibling who had died of hypoglycaemia in infancy. ${ }^{9}$ Nesidioblastosis has also been documented as a predominant manifestation of multiple endocrine adenomatosis in eight family members over three generations. ${ }^{11}$
With greater awareness of the disease, the diagnosis of nesidioblastosis should be suspected early and confirmed within a few days of birth. Insulin release normally falls as the blood glucose concentration decreases. ${ }^{48}$ During severe hypoglycaemia insulin concentrations should be undetectable. Low plasma concentrations of free fatty acids and blood ketones simultaneously support the diagnosis of hyperinsulinism as insulin inhibits lipolysis and hence production of ketone bodies. ${ }^{49}$ The absence of ketone bodies as an alternative energy source for cerebral function during hypoglycaemia may explain the high incidence of cerebral damage in these infants. The excess insulin also directs glucose to hepatic glycogen synthesis, probably one factor responsible for the hepatomegaly. The anabolic effect of insulin is also responsible for the high birth weight of some infants.

Though the diagnosis should always be confirmed by measuring plasma insulin, alternative and rapid methods of diagnosis are helpful. The glucose infusion rate, necessary to maintain normoglycaemia, should be calculated. Glucose infusion rates greater than $10 \mathrm{mg} / \mathrm{kg} / \mathrm{minute}$ in absence of hyperglycaemia or glycosuria are diagnostic of hyperinsulinism (glucose production in the normal newborn is $5-8 \mathrm{mg} / \mathrm{kg} /$ minute). ${ }^{50}$ All our patients required glucose infusion rates of between $10-25 \mathrm{mg} / \mathrm{kg} /$ minute. Diazoxide has been the most widely used drug, inducing hyperglycaemia by mobilising glucagon, stimulating catecholamine secretion, and directly inhibiting insulin release. However, fluid retention is common and three patients developed cardiac failure that responded rapidly to antifailure treatment. Glucagon and prednisolone have been used with varying degrees of success. Somatostatin or a long acting analogue is now the drug of choice and particularly useful in the preoperative preparation of the infant who develops cardiovascular problems from fluid overload and diazoxide treatment. Because somatostatin inhibits not only insulin release but also adrenocorticotrophic hormone and glucagon secretion its use should be combined with glucagon ${ }^{51}$ and possibly with cortisol. Tolerance to somatostatin may develop so that surgery is still necessary, although some patients have been given long term treatment. ${ }^{52}$

The time interval between onset of symptoms and operation reported in the literature was $5.55 \pm 1.53$ months in developmentally normal children compared with $9.65 \pm 2.6$ months in the mentally retarded infants. ${ }^{1}$ In our series the average delay between onset of symptoms and operation was $2 \cdot 2$ months excluding four patients who came to surgery aged between 2.5 and 5 years. Only three patients, two of whom were referred from abroad, had established neurological deficit.

Surgery is indicated when normoglycaemia cannot be reliably maintained despite adequate dosages of glucose, diazoxide, chlorothiazide, and somatostatin. Some patients have been maintained for prolonged periods with medication, notably long term somatostatin ${ }^{36}$ but the effect on glucagon and growth hormone release remains a potential risk. They still require regular frequent high carbohydrate-containing 
feeds but are at risk of developing hypoglycaemia that may result in brain damage, especially during episodes of stress or intercurrent infection. In 1977, Thomas et al found that at least $50 \%$ of infants undergoing pancreatic resection were mentally retarded at the time of surgery. ${ }^{1}$ The incidence of neurological damage was still around $33 \%$ in recently reviewed series. It is anticipated that with the increased awareness of the disease and the safety of surgical treatment, neurological sequelae will be prevented in the majority of patients.

Diffuse involvement of the pancreas is more common that localised lesions especially in infancy. Of 188 cases published in the literature from 1982 to 1989,137 were in infants under one year old, while 61 occurred in older children. In infants, only $7 \%$ (10 cases) had localised lesions compared with $40 \%$ ( 24 cases) in the older children. Fifteen infants $(11 \%)$ had mixed lesions. Limited resection for localised lesions should be reserved for the older age group as diffuse involvement commonly coexists in infants with an apparent localised lesion.

In the majority of patients surgical resection involves a subtotal pancreatectomy. The extent of the resection continues to be controversial. The original subtotal pancreatectomy described by Gross constituted a $65 \%$ resection. ${ }^{53}$ The resection was carried out to the left of the superior mesenteric vessels and was attended by a $50 \%$ recurrence rate. ${ }^{54}$ This high recurrence rate spurred surgeons on to carry out more radical resections. Harkin et al in 1971 recommended an initial $80-90 \%$ resection followed by a total pancreatectomy for surgical failures. ${ }^{55}$ McFarland et al went even further advocating formal pancreatoduodenectomy. ${ }^{56}$ Martin et al in 1984 , reviewed the results according to the extent of resection in 181 patients. ${ }^{33}$ Of 118 patients having subtotal $(<80 \%)$ resection, $45 \%$ required additional treatment and $26 \%$ needed reoperation for persistent hypoglycaemia. In comparison, of 63 patients with near total $(>80 \%$ ) pancreatectomy, only $20 \%$ needed additional medication and $8 \%$ reoperations. ${ }^{2}$ In the review of Thomas et al of 159 cases, $28 \%$ of patients undergoing subtotal pancreatectomy required a second operation compared with $5 \%$ of patients with a $95-98 \%$ pancreatectomy. ${ }^{43}$

Review of the recent publications indicate that there is still ambiguity in reporting the extent of resection. Resections of less than $80 \%$, that is, to the left of superior mesenteric vessels, are associated with recurrence rate of $26 \%$. A primary $99 \%$ resection was performed in six patients $(3 \%)$ with no recurrence. The majority of the surgeons carried out resections varying between 80 and $95 \%$, with recurrence rates of $24 \%$ to $16 \%$ respectively (table). Close scrutiny

Extent of resection (literature review 1982-9)

\begin{tabular}{lll}
\hline $\begin{array}{l}\text { Resection } \\
(\%)\end{array}$ & $\begin{array}{l}\text { No (\%) } \\
\text { of patients }\end{array}$ & $\begin{array}{l}\text { Reoperation } \\
(\%)\end{array}$ \\
\hline 99 & $6(3)$ & - \\
$90-95$ & $78(40)$ & $16 \cdot 6$ \\
$80-90$ & $68(34)$ & $23 \cdot 5$ \\
$<80$ & $41(21)$ & $26 \cdot 8^{*}$ \\
\hline
\end{tabular}

${ }^{*}$ Four of 11 patients required a third resection. of the operative reports indicates that in many cases the resection was well short of that described above as an adequate $95 \%$ resection and this may account for the high recurrence rate. Only one of our patients had an unsatisfactory response to pancreatic resection and required a second resection. In retrospect, it was obvious that this infant did not have a full 95\% pancreatic resection at initial surgery.

We have no experience with portal blood sampling at operation to determine the adequacy of pancreatic resection as advocated by Carcassone $e t a l^{24}$ and Kishi et al. ${ }^{26}$ Hyperglycaemia or recurrent hypoglycaemia is common in the early postoperative period, ${ }^{130} 55$ but once normoglycaemia has been established for a few months there is minimal risk of subsequent late complications after surgical resection.

Awareness of the disease entity, early diagnosis, and appropriate treatment are essential if irreversible brain damage is to be prevented. A $95 \%$ pancreatectomy has proved highly effective and patients not responding to medical treatment should be referred for surgery early and not as a last resort.

1 Thomas CG, Underwood MD, Carney CN, et al. Neonata infantile hypoglycemia due to insulin excess. Ann Surg 1977;185:505-7.

2 Laidlaw GF. Neisidioblastoma, the islet tumour of pancreas. Am F Pathol 1938;14:125-39.

3 Yakovac WC, Baker L, Hummeler K. Beta cell nesidioblastosis in idiopathic hypoglycemia in infancy. $\mathcal{f}$ Pediat blastosis in idiop
1971;79:226-31.

4 Aynsley-Green A. Nesidoblastosis of the pancreas in infancy. Dev Med Child Neurol 1981;23:372-9.

5 Aynsley-Green A, Polak JM, Bloom SR, et al. Nesidioblastosis of the pancreas: definition of the syndrome and the management of the severe neonatal hyperinsulinaemic hypoglycaemia. Arch Dis Child 1981;56:496-508.

6 Woolf DA, Leonard JV, Trembath RC, Pembrey ME, Grant DB. Nesidioblastosis: evidence for autosomal recessive inheritance. Arch Dis Child 1991;66:529-30.

7 Woo D, Scopes JW, Polak JM. Idiopathic hypoglycaemia in sibs with morphological evidence of nesidioblastosis of the pancreas. Arch Dis Child 1976;51:528-31.

8 Schwartz SS, Rich BH, Lucky AW, et al. Familial nesidioblastosis: severe neonatal hypoglycemia in two families. flastosis: severe neonatal

9 Becker K, Wendel U, Przyrembel H, et al. Beta cell nesidioblastosis. Eur $\mathcal{f}$ Pediatr 1978;127:75-89.

10 Low LC, Yu EC, Chow OK, et al. Hyperinsulinism in infancy. Aust NZ F Surg 1989;25:174-7.

11 Vance JE, Stoll RW, Kitabachi AE, et al. Familial nesidioblastosis as the predominant manifestation of multiple endocrine adenomatosis. Am F Med 1972;52:211-27.

12 Aynsley-Green A, Polak JM, Keeling J, et al. Averted sudden neonatal death due to pancreatic nesidioblastosis. Lance 1978;i:550-1.

13 Polak JM, Wigglesworth JS. Islet cell hyperplasia and sudden infant death. Lancet 1976;ii:570-1.

14 Cox JN, Guelpa G, Terrapon M. Islet cell hyperplasia and sudden infant death. Lancet 1976; ii:739-40.

15 Kirk JM, Di Silvio L, Hindmarsh PC, Brook CG. Somatostatin analogue in the short term management of hyperstatin analogue in the short term managem
insulinism. Arch Dis Child 1988;63:1493-4.

16 Hawdon JM, Ward Platt MP, Lamb WH, Aynsley-Green A. Tolerance to somatostatin analogue in a preterm infant with islet cell dysregulation syndrome. Arch Dis Child 1991;66: islet cell

17 Spitz L, Buick RG, Grant DB, et al. Surgical treatment of nesidioblastosis. Pediatric Surgery. International 1986;1 26-9.

18 Tudor RB. Neonatal hypoglycemia report. No 3. Bismark ND: Childhood Gastroenterology/Endocrinology Registry, 1987

19 Welch KJ, Hypoglycemia. In: Welch KJ, Randolph JG, Ravitch MM, et al. eds. Pediatric surgery. Chicago: Yea Book Medical Publishers, 1986:1100.

20 Landau H, Perlman M, Meyer S, et al. Persistent neonatal hypoglycemia due to hyperinsulinism: medical aspects. Pediatrics 1982;70:440-6.

21 Kramer JL, Bell MJ, DeSchryver $\mathrm{K}$, et al. Clinical and histologic indications for extensive pancreatic resection in nesidioblastosis. Am F Surg 1982;143:116-9.

22 Moazam F, Rodgers BM, Talbert JL, et al. Near-tota pancreatectomy in persistent infantile hypoglycemia. Arch Surg 1982;117:1151-4.

23 Zuppinger $K$. Disorders of the endocrine pancreas. Prog Pediatr Surg 1983;16:51-61.

24 Carcassone M, Deharue A, LeTourneau JN. Surgical treat- 
ment of organic pancreatic hypoglycemia in the pediatric age. 7 Pediatr Surg 1983;18:75-9.

25 Zuniga O, Golden MP, Sargeant DT, et al. Persistent leucine sensitivity following partial pancreatectomy and diazoxide treatment. Therapeutic response. Am $\mathcal{F}$ Dis Child 1983;137: 393-5.

26 Kishi $\mathrm{K}$, Odachi $\mathrm{T}$, Inoue $\mathrm{M}$, et al. Transumbilical portal vein catheterization and insulin analysis in an infant with hypoglycemia. Ipn I Surg 1983;13:261-3.

27 Campbell JR, Rivers SP, Harrison MW, et al. Treatment of hypoglycemia in infants and children. Am $\mathcal{F}$ Surg 1983;146: 21-8.

28 Langer JC, Filler RM, Wesson DE, et al. Surgical management of persistent neonatal hypoglycemia due to islet cell ment of persistent neonatal hypoglycemia
dysplasia. F Pediatr Surg 1984;19:786-91.

29 Simmons PS, Telander RL, Carney JA, et al. Surgical management of hyperinsulinemic hypoglycemia in children. management of hyperinsulinem.

30 Gough $\mathrm{MH}$. The surgical treatment of hyperinsulinism in infancy and childhood. Br $\mathcal{J}$ Surg 1984;71:75-8.

31 Goudswaard WB, Zwierstra RP, Houthoff HJ. Surgical treatment of organic hyperinsulinism in infancy. $Z$ Kinderchir 1984;39:91-5.

32 Saul W, Willberg B, Bremer HJ. Surgical therapy of nesidioblastosis. Z Kinderchir 1984;39:96-8.

33 Martin LW, Ryckman FC, Sheldon CA. Experience with $95 \%$ pancreatectomy and splenic salvage for neonatal nesidioblastosis. Ann Surg 1984;200:355-62.

34 Jacobs DG, Haka-Ikse K, Wesson DE, et al. Growth and development in patients operated on for islet cell dysplasia. f Pediatr Surg 1986;21:1184-9.

35 Upp JR, Ishizuka J, Lobe TE, et al. Somatostatin secretion in cultured human islet cells from patients with nesidioblastosis: a compensatory mechanism? f Pediatr Surg 1987;22:1185-6.

36 Wilson DC, Carson DJ, Quinn RJ, et al. Long-term use of somatostatin analogue SMS 201-995 in the treatment of hypoglycaemia due to nesidioblastosis. Acta Paediatr Scand $1988 ; 77: 467-70$.

37 Lischka A. Preoperative management of newborn infants with hyperinsulinemic hypoglycemia. Klin Padiatr 1987; 199:356-60.

38 Aynsley-Green A. The management of islet cell dysregulation syndrome in infancy and childhood. $Z$ Kinderchir 1988;43: 267-72.

39 Warden MJ, German JC, Buckingham BA. The surgical management of hyperinsulinism in infancy due to nesidioblastosis. F Pediatr Surg 1988;23:462-5.

40 Hummer HP, Bohles $\mathrm{H}$ Giedl I, et al 7/8 pancreatectomy for treatment of nesidioblastosis. Z Kinderchir 1988;43.281-3.
41 Amendt P, Kohnert KD, Kunz J. The hyperinsulinaemic hypoglycemia in infancy: a study of six cases. Eur $\mathcal{F}$ Pediatr 1988;148:107-12

42 Synn AY, Mulvihill SJ, Fonkalsrud EQ. Surgical disorders of the pancreas in infancy and childhood. Am $\mathcal{f}$ Surg $1988 ; 156: 201-5$.

43 Thomas CG, Guenca RE, Azizkhan RG, et al. Changing concepts of islet dysplasia in neonatal and infantile hyperinsulinism. World 7 Surg 1988;12:598-609.

44 Goosens A, Gepts W, Saudubray JM, et al. Diffuse and focal nesidioblastosis. A clinicopathological study of 24 patients with persistent neonatal hyperinsulinemic hypoglycemia. with f Surg Pathol 1989;13:766-75.

45 Vane DW, Grosfeld JL, West KW, et al. Pancreatic disorders in infancy and childhood: experience with 92 cases. in infancy and childhood:

46 Gabbay HK. Case records of the Massachussets General Hospital. N Engl f Med 1978;299:241-8.

47 Heitz PU, Kloppel G, Hacki WH, et al. Nesidioblastosis: the pathological basis of persistent hyperinsulinemic hypoglycemia in infants. Diabetes 1977;26:632-42.

48 Turner RC, Heding LG. Plasma proinsulin, C-peptide and insulin in diagnostic suppression tests for insulinomas. Diabetologica 1977;13:571-7.

49 Stanley CA, Baker L. Hyperinsulinism in infancy: diagnosis by demonstration of abnormal response to fasting hypoglycemia. Pediatrics 1976;57:702-11.

50 Bier DM, Leak RD, Haymond MW, et al. Measurement of true glucose production rates in infancy and childhood with 6-6-dideutero glucose. Diabetes 1977;26:1016-23.

51 Bougnères $P-F$, Landier $F$, Garnier $P$, Job J-C, Chaussain $J-L$. Treatment of insulin excess by continuous subJ-L. Treatment of insulin excess by continuous subcutaneous infusion of somatostatin

52 Glaser B, Landaw H. Long term treatment with somatostatin analogue SMS 201-995: alternative to pancreatectomy in persistent hyperinsulinaemic hypoglycaemia of infancy. Digestion 1990;45(suppl 1):27-35.

53 Gross RE. The surgery of infancy and childhood. Philadelphia: WB Saunders, 1953 .

54 Hamilton JP, Baker L, Kaye R, et al. Subtotal pancreatectomy in the management of severe persistent idiopathic hypoin the management of severe persistent idiopa
glycemia in children. Pediatrics 1967;39:49-58.

55 Harken AH, Filler RM, AvRuskin TW, et al. The role of 'total' pancreatectomy in the treatment of unremitting hypoglycemia of infancy. F Pediatr Surg 1971;6:284-9.

56 McFarland JO, Gillette FS, Zwemer RJ. Total pancreatectomy for hyperinsulinism in infants. Surgery 1965;57: 313-8. 